\title{
Effects of perfluorooctane sulfonate on ion channels and glutamate-activated current in cultured rat hippocampal neurons
}

\author{
Chun-yang Liao ${ }^{\mathrm{a}, \mathrm{b}}$, Lin Cui ${ }^{\mathrm{b}}$, Qun-fang Zhou ${ }^{\mathrm{b}}$, Shu-min Duan ${ }^{\mathrm{c}}$, Gui-bin Jiang ${ }^{\mathrm{b}, *}$ \\ a Yantai Institute of Coastal Zone Research for Sustainable Development, Chinese Academy of Sciences, Yantai, \\ Shandong 264003, China \\ b State Key Laboratory of Environmental Chemistry and Ecotoxicology, Research Center for Eco-Environmental Sciences, Chinese Academy of Sciences, \\ P.O. Box 2871, Beijing 100085, China \\ ' Institute of Neuroscience and State Key Laboratory of Neurobiology, Shanghai Institutes for Biological Sciences, Chinese Academy of Sciences, \\ Shanghai 200031, China
}

\section{A R T I C L E I N F O}

\section{Article history:}

Received 4 August 2008

Received in revised form

25 November 2008

Accepted 28 November 2008

Available online 9 December 2008

\section{Keywords:}

Perfluorooctane sulfonate (PFOS)

Neurotoxicity

Potassium channel

Sodium channel

Glutamate-activated current

\begin{abstract}
A B S T R A C T
Concern on an emerging persistent contaminant, perfluorooctane sulfonate (PFOS), is increasingly growing. Although the fate, transport, distribution and bioaccumulation of PFOS have been documented, its toxicological effects especially neurotoxicity remain largely unknown. In this study, the effects of PFOS on ion channels including potassium and sodium channels and exogenous glutamate-activated current in cultured rat hippocampal neurons were examined, based on whole-cell patch-clamp recording. PFOS markedly increased two subtypes of potassium currents, including transient outward current and delayed rectifier current, at doses over $10 \mu \mathrm{M}$. PFOS did not affect the amplitude of sodium current at all administrated doses $(1,10$ or $100 \mu \mathrm{M})$ but clearly shifted the activation current-voltage curve toward negatively potential. Further, PFOS significantly altered the glutamate-activated current at all doses. Taken together these findings indicated that PFOS disturbs the neuronal physiological processes, which revealed the damage of this pollutant to nerve system and will be helpful for further exploration to its underlying mechanism.
\end{abstract}

(C) 2009 Published by Elsevier B.V.

\section{Introduction}

Perfluorinated compounds (PFCs) are a class of emerging persistent contaminants. These chemicals are fully fluorinated man-made chemicals with unique properties that make them useful in wide array of industrial and household applications such as refrigerants, surfactants and polymers, and as components of pharmaceuticals, fire retardants, lubricants, adhesives, cosmetics, paper coatings, and insecticides (Renner, 2001; Giesy and Kannan, 2001, 2002; Houde et al., 2006a; Lau et al., 2007). Perfluorooctane sulfonate (PFOS) is the terminal degradation end product of many commercially used perfluorinated organic products and is the predominant PFC detected in multiple environmental matrices including water, air, sediment and biota (Kannan et al., 2001, 2002; Martin et al., 2002; Taniyasu et al., 2005; Houde et al., 2006b; Yeung et al., 2006). The widespread application, environmental persistence and bioaccumulative potential of PFOS increase governmental pressure and arise intense scientific and regulatory interest (Lau et al., 2004,

\footnotetext{
* Corresponding author. Tel.: +86 106284 9129; fax: +861062849937.

E-mail address: gbjiang@rcees.ac.cn (G.-b. Jiang).
}

2007; Kennedy et al., 2004; Andersen et al., 2006; Houde et al., 2006a; Butenhoff et al., 2006).

The exceptional stability of PFOS also makes it potentially hazardous to wildlife and human. Human may be exposed to PFOS through air, water, food and household dust due to the global occurrence of PFOS in environment (Renner, 2001; Lau et al., 2007). PFOS is readily absorbed by organisms through oral uptake but difficulty eliminated out due to several years of half-life (Burris et al., 2002). Increasing evidences show that PFOS exposure can induce various toxic effects in animals such as hepatotoxicity, developmental, reproductive and systemic toxicity, interferences in thyroid hormone level, mitochondrial bioenergetics and cell-cell communication, neuroendocrine dysfunction and carcinogenicity (Hu et al., 2002, 2003; Austin et al., 2003; Lau et al., 2004; Kennedy et al., 2004). Using isolated guinea-pig ventricular myocyte and cultured rat cerebellar Purkinje cell as in vitro models, Harada et al. (2005, 2006) demonstrated the effects of PFOS on the calcium, potassium and sodium channels and action potential, based on whole-cell patch-clamp recording. Although there have been growing studies on fate, transport, distribution and bioaccumulation of PFOS, its toxicological effects especially neurotoxicity is still poorly understood. In this work, the primary cultured rat hippocampal neuron was used as an in vitro model to explore the effects of PFOS on 
(A)

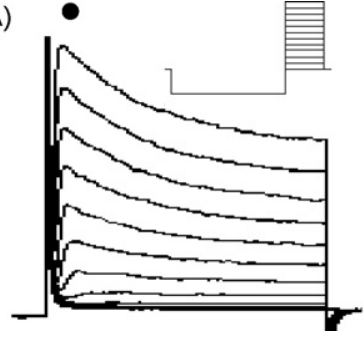

(B)
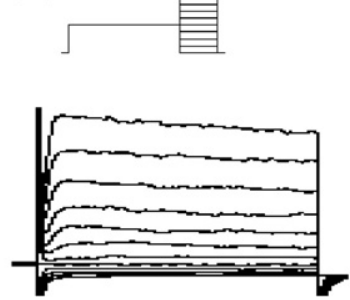

(C)

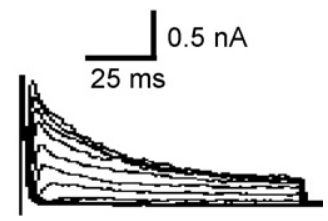

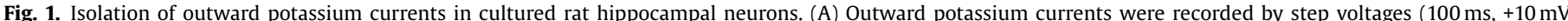

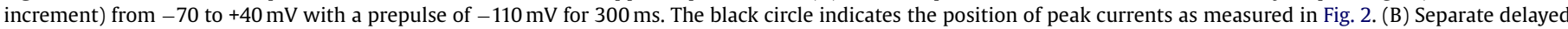

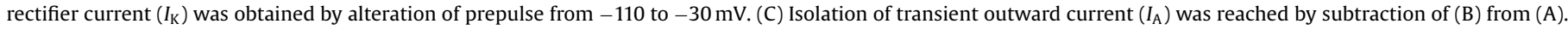
Insets refer to protocols used. Scales, $0.5 \mathrm{nA}, 25 \mathrm{~ms}$. For this and subsequent figures, the pipette potential was held at $-70 \mathrm{mV}$.

potassium, sodium and glutamate-activated currents and the underlying mechanism.

\section{Materials and methods}

\subsection{Drugs and application}

Heptadecafluorooctane sulfonic acid potassium salt $\left[\mathrm{CF}_{3}\left(\mathrm{CF}_{2}\right)_{7} \mathrm{SO}_{3} \mathrm{~K}, \mathrm{MW}\right.$ 538.22, 98\%] was used as a standard for PFOS and purchased from Fluka (Buchs, Switzerland). Appropriate amount of PFOS was dissolved in dimethyl sulfoxide (DMSO; Sigma, St. Louis, MO) giving a $100 \mathrm{mM}$ stock solution. The working solutions were freshly prepared by dilution of the stock solution with the extracellular solution (ECS) just before use. Other reagents were from Sigma-Aldrich (St. Louis, MO) unless otherwise stated. For recording the potassium and sodium currents, drugs were applied to neurons by continuing perfusion using a HL-2 constant flow pump (Shanghai Huxi Analytical Instrument Co., China). For recording the glutamate-activated current, a miniature home-made Y-tube manipulated near the cell body (within $100 \mu \mathrm{m}$ ) was used to ensure rapid (within $100 \mathrm{~ms}$ ) application of PFOS-containing saline to the neuron with minimal dilution or mixing during electrophysiological recording. The solutions were held in reservoirs higher than the recording bath and drawn through the arms of the Y-tube, which are of larger diameter tubing (PE 50) than the stem (PE 10).

\subsection{Primary cell culture}

The use and care of animals follow the guideline of the Shanghai Institutes for Biological Sciences Animal Research Advisory Committee. Primary hippocampal

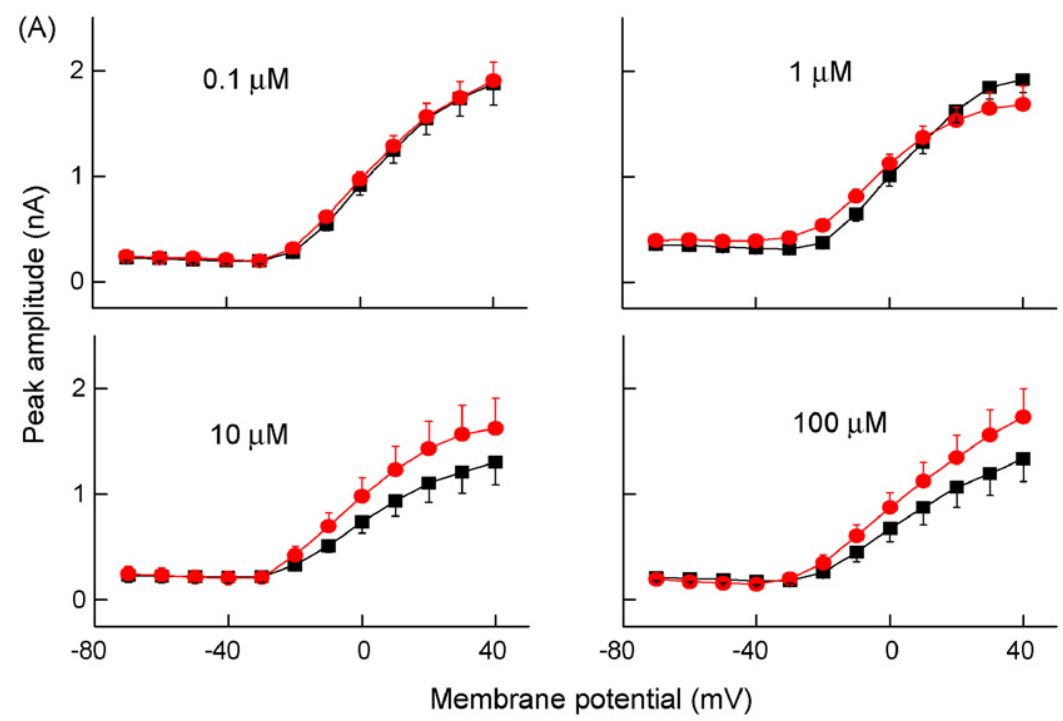

(B)

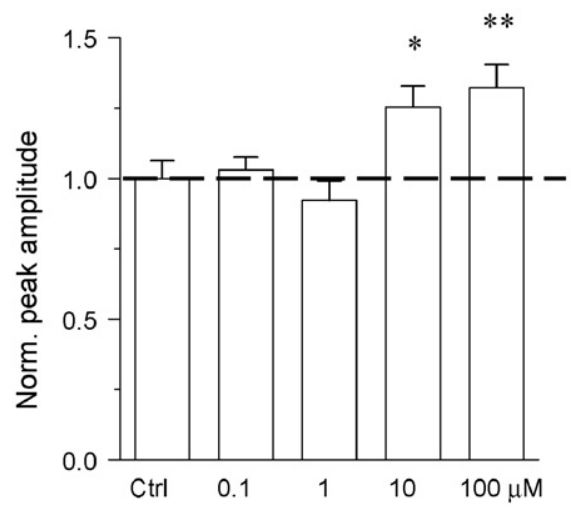

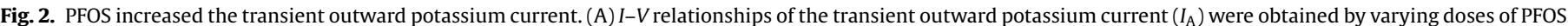

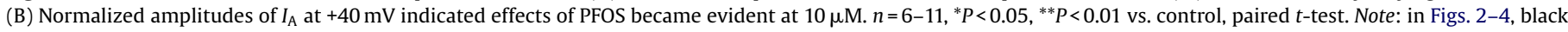

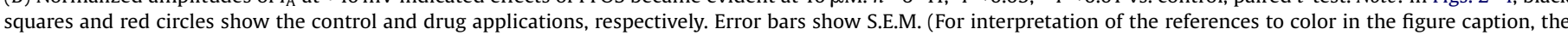
reader is referred to the web version of the article.) 
(A)

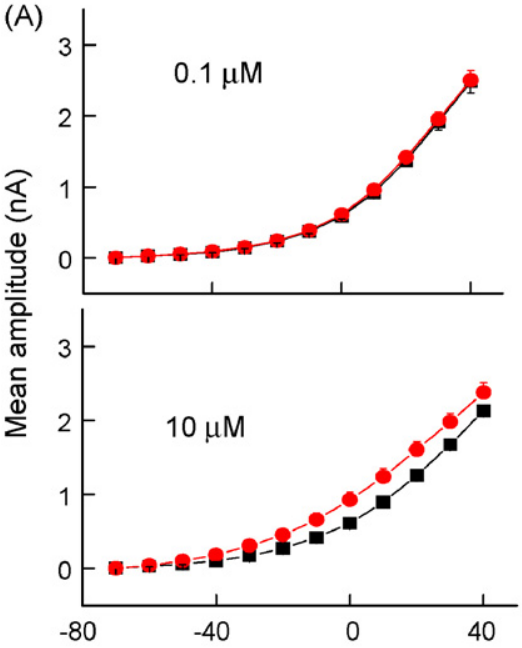

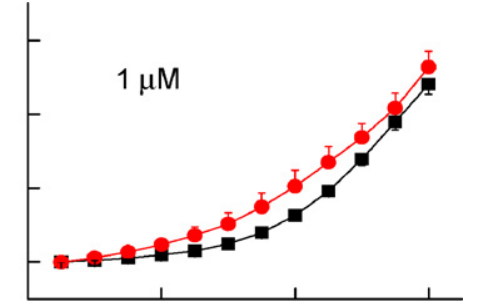

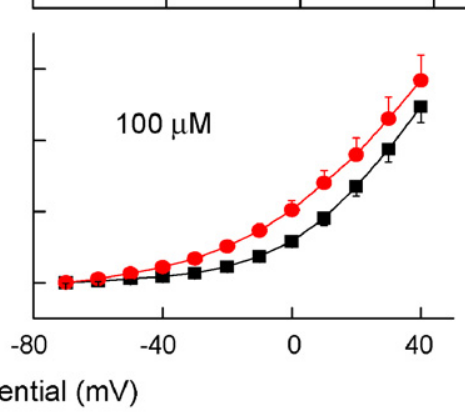

(B)

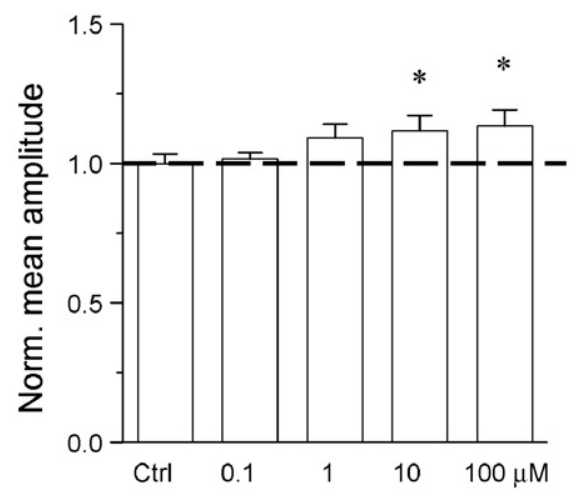

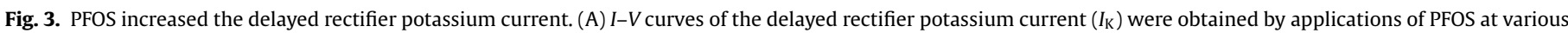

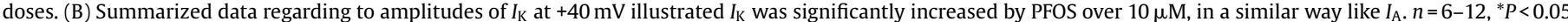
vs. control, paired $t$-test. Error bars indicate S.E.M.

neuron was cultured as reported previously (Shen et al., 2006). Briefly, hippocampi were dissected from embryonic day 18 SD rats and digested in $0.25 \%$ trypsin (Sigma) for $12-15$ min at $37^{\circ} \mathrm{C}$, followed by gentle trituration. Dissociated cells were plated at a density of 25,000-60,000 cells/mL on poly-D-lysine-coated $35 \mathrm{~mm}$ dishes (Costar, Cambridge, MA) in Dubecco's Modified Eagle Medium (DMEM; GIBCO, Grand Island, NY) supplemented with 10\% heat-inactivated fetal bovine serum (GIBCO) and $10 \%$ Ham's F-12 (GIBCO). After $24 \mathrm{~h}$ in vitro, half of the medium was changed to serumfree neurobasal (NB) medium with $2 \%$ B27 supplement (GIBCO) and $0.25 \%$ glutamine (Sigma). Thereafter, half of the medium was replaced twice a week with NB medium containing $2 \%$ B27 supplement and $0.25 \%$ glutamine. After 5 days in vitro (DIV 5), cytosine arabinoside was added at $2-4 \mu \mathrm{M}$ to inhibited glial cell proliferation.

\subsection{Whole-cell recording}

Voltage-clamp recordings were conducted pre- and post-treatment of PFOS at DIV 8-15 neurons from at least three separate cultures according to the whole-cell patch-clamp technique. Currents were recorded with a Multiclamp $700 \mathrm{~A}$ or $700 \mathrm{~B}$ amplifier, low-pass filtered at $1 \mathrm{kHz}$ using the amplifier circuitry, sampled at $10 \mathrm{kHz}$ and stored in a computer using a Digidata 1320A interface and Clampex 8.2 software (all from Axon Instrument, Foster City, CA). The patch pipettes were pulled by a P-97 micropipette puller from borosilicate glass capillaries (Sutter Instruments, Novato, CA). The pipette resistance was 2-6 M $\Omega$ when filled with intracellular solution (ICS). Neurons tested were held at $-70 \mathrm{mV}$ during electrophysiological recordings. For recording the potassium current, the ICS contained (in $\mathrm{mM}$ ) 136.5 K-gluconate, 17.5 $\mathrm{KCl}, 9 \mathrm{NaCl}, 1 \mathrm{MgCl}_{2}, 10$ HEPES, 0.2 EGTA, and $2 \mathrm{Na}-\mathrm{ATP}$ ( $\mathrm{pH}$ 7.2). The ECS contained (in mM) $145 \mathrm{NaCl}, 3 \mathrm{KCl}, 3 \mathrm{CaCl}_{2}, 2 \mathrm{MgCl}_{2}, 10$ HEPES, 8 D-glucose, 0.0005 tetrodotoxin (TTX), and $0.1 \mathrm{CdCl}_{2}$ ( $\mathrm{pH} 7.3$ ). For recording the sodium current, the ICS contained (in mM) $135 \mathrm{CsCl}, 10$ TEA-Cl, $3 \mathrm{MgCl}_{2}, 10$ HEPES, 10 EGTA, 3 Na-ATP, $0.3 \mathrm{Na}-\mathrm{GTP}$ (pH 7.2). The ECS contained (in $\mathrm{mM}$ ) $60 \mathrm{CsCl}, 75 \mathrm{NaCl}, 20$ TEA-Cl, $1 \mathrm{BaCl}_{2}, 2$ 4-AP, $2 \mathrm{MgCl}_{2}, 10$ HEPES, 10 D-glucose, and $0.1 \mathrm{CdCl}_{2}(\mathrm{pH} 7.3)$. For recording the glutamate-activated current, the ICS was same as that of recording the potassium current and the ECS was $\mathrm{Mg}^{2+}$-free ECS containing (in mM) $145 \mathrm{NaCl}, 3 \mathrm{KCl}, 3 \mathrm{CaCl}_{2}, 10$ HEPES, 8 glucose, 0.001 glycine, $0.0005 \mathrm{TTX}$ ( $\mathrm{pH} 7.3$ ). All experiments were performed at room temperature and there is no discernable mortality of cells throughout each electrophysiological recording.

\subsection{Data analysis}

Data were analyzed with Clampfit 9.0 (Axon Instrument) and presented as mean \pm S.E.M. Statistical comparisons were made using analysis of variance (ANOVA) or $t$-test where appropriate and $P<0.05$ was considered significant.

\section{Results}

\subsection{Effect of PFOS on voltage-dependent potassium channel currents}

Outward potassium currents of neurons were examined with a bath saline containing both TTX and $\mathrm{Cd}^{2+}$ to eliminate possible competing inward $\mathrm{Na}^{+}$and $\mathrm{Ca}^{2+}$ currents (Meyers et al., 1992; Richmond et al., 1995). Two subtypes of $\mathrm{K}^{+}$currents, transient outward current $\left(I_{\mathrm{A}}\right)$ and delayed rectifier current $\left(I_{\mathrm{K}}\right)$, were recorded with a series graded concentrations of PFOS applications. Fig. 1 showed the example recordings of both subtypes of $\mathrm{K}^{+}$currents and their isolation. Outward $\mathrm{K}^{+}$currents, containing both $I_{\mathrm{A}}$ and $I_{\mathrm{K}}$, were evoked by step voltages $(100 \mathrm{~ms}, 10 \mathrm{mV})$ from -70 to $+40 \mathrm{mV}$ with a prepulse of $-110 \mathrm{mV}$ for $300 \mathrm{~ms}$. Independent $I_{\mathrm{K}}$ was in turn recorded with the same protocol by altering prepulse from -110 to $-30 \mathrm{mV}$. Isolation of $I_{\mathrm{A}}$ was reached by subtraction of $I_{\mathrm{K}}$ from total outward currents recorded (Duan and Cooke, 1999). The current densities of $I_{\mathrm{A}}$ and $I_{\mathrm{K}}$ were shown in Figs. 2A and 3A. The 
(A)

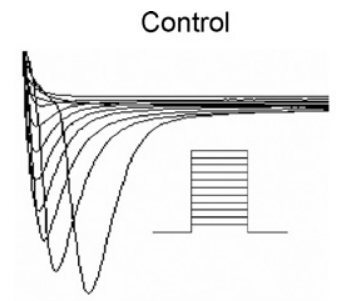

(B) $\quad \begin{array}{llll}-60 & -30 & 0 & 30\end{array}$

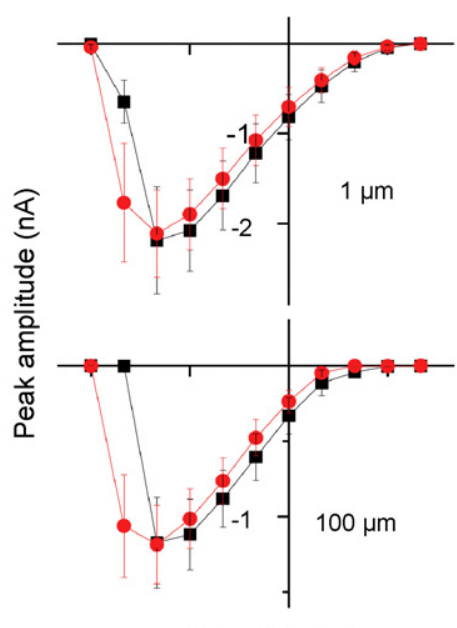

Potential (mV)
PFOS
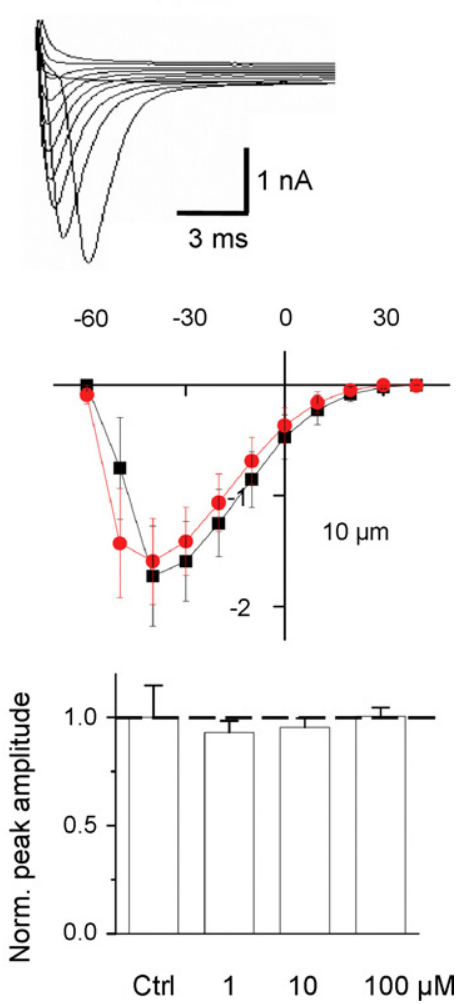

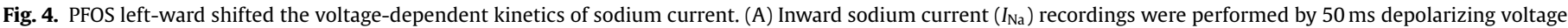

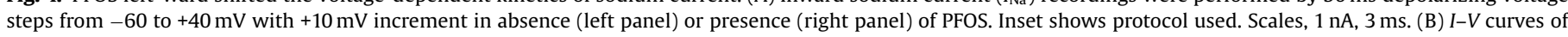

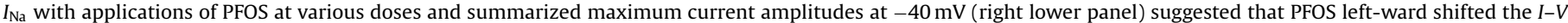
curves but not increased peak amplitudes. $n=8-10, P>0.05$ vs. control, paired $t$-test. Error bars represent S.E.M.

effects of PFOS became evident at $10 \mu \mathrm{M}$ and the total magnifications were approximately 25 and $30 \%$ for $I_{\mathrm{A}}$ and $I_{\mathrm{K}}$, respectively $\left(P<0.05, t\right.$-test). The maximum amplitudes of $I_{\mathrm{A}}$ and $I_{\mathrm{K}}$ at $+40 \mathrm{mV}$ in each series of recordings were compared subsequently in Figs. 2B and 3B. The current increase was common to two subtypes of $\mathrm{K}^{+}$channels tested and the dose-response relationships were observed, which demonstrated the actions of PFOS on potassium channels.

\subsection{Effect of PFOS on voltage-dependent sodium channel current}

The effect of PFOS on the voltage-dependent sodium current $\left(I_{\mathrm{Na}}\right)$ was examined by means of a $\mathrm{Cd}^{2+}$-containing ECS and a $\mathrm{Cs}^{+}-$ rich ICS. The $I_{\mathrm{Na}}$ was recorded by $50 \mathrm{~ms}$ depolarizing voltage steps from -60 to $+40 \mathrm{mV}$ with $+10 \mathrm{mV}$ increment in the absence or presence of various doses of PFOS $(1,10$ and $100 \mu \mathrm{M})$. As shown in Fig. 4B, PFOS negatively shifted the $I-V$ curve of $I_{\mathrm{Na}}$ but not increased peak amplitudes at all administrated doses. Similarly the maximum amplitudes of $I_{\mathrm{Na}}$ at $-40 \mathrm{mV}$ in each series of recordings were averaged and the comparison results also demonstrated that no significant effects were found in amplitudes by PFOS (Fig. 4B, right lower panel).

\subsection{Effect of PFOS on glutamate-activated current}

The exogenous glutamate-activated inward currents were recorded by gravity ejection of glutamate $(100 \mu \mathrm{M})$ in absence or presence of PFOS at various concentrations through a pair of
(A)

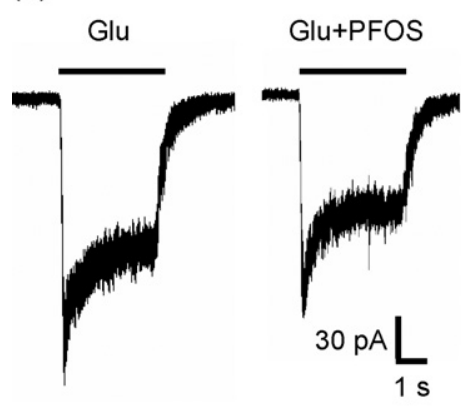

(B)

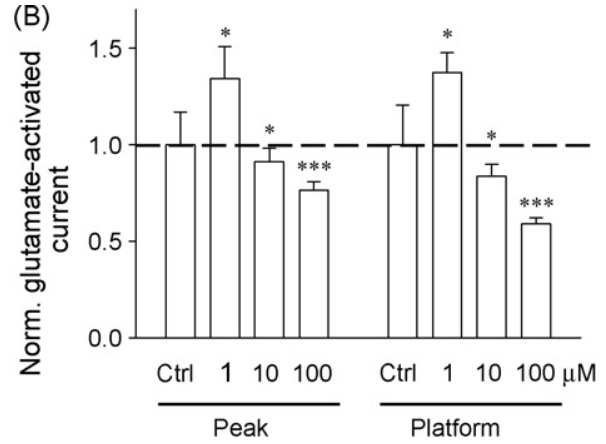

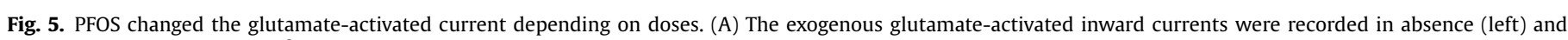

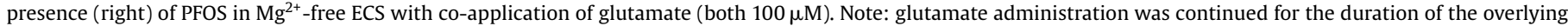

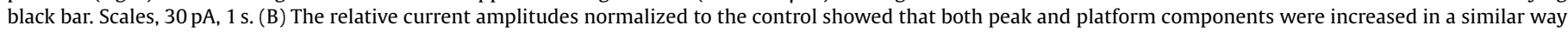

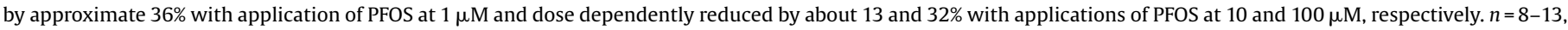
${ }^{*} P<0.05,{ }^{* * *} P<0.001$ vs. control, paired $t$-test. Error bars show S.E.M. 
parallel polyethylene flow pipes. Glutamate induced currents in all neurons tested in $\mathrm{Mg}^{2+}$-free ECS with co-applications of $1 \mu \mathrm{M}$ glycine for magnification of the current and $0.5 \mu \mathrm{M}$ TTX for inhibition of action potential. Fig. 5A showed the current response of a neuron induced by exogenous glutamate before and after $100 \mu \mathrm{M}$ PFOS administration. The current reached a peak quickly (within $100 \mathrm{~ms}$ ), then decayed to a steady-state level (platform) during glutamate application, and finally terminated with washout of ECS. It is known that the glutamate-activated current is induced by action of specific ligand, for example PFOS in this study, with $\alpha$-amino-3hydroxy-5-methyl-4-isoxazolepropionic acid (AMPA)/kainate and $\mathrm{N}$-methyl-D-aspartate (NMDA) receptors located on cellular membrane surface. The peak and platform reflect the AMPA/kainate and NMDA components of glutamate-activated current, respectively. Investigation of the glutamate-activated current with PFOS might preliminarily explore the effects of PFOS on AMPA/kainate and NMDA receptors. To examine whether the glutamate-activated current runs down over time, the currents were repeatedly recorded by ejection of glutamate at intervals of $5 \mathrm{~min}$ or more with $\mathrm{Mg}^{2+}$-free ECS washout. We found that the currents did not decay over time under this experimental condition. So each peak or platform value of glutamate-activated currents was averaged by at least two repeated recordings with intervals of $5 \mathrm{~min}$ or more. After normalization to the control, the relative current amplitudes were displayed in Fig. 5B, indicating both peak and platform components in a similar way were elevated by about $36 \%$ over the control with application of PFOS at $1 \mu \mathrm{M}$ and dose dependently suppressed by around 13 and $32 \%$ with applications of PFOS at 10 and $100 \mu \mathrm{M}$, respectively $(P<0.05$, paired t-test).

\section{Discussion}

The present study showed evidences that PFOS disturbed the normal physiological processes of primary cultured rat hippocampal neurons, such as ion channels and glutamate-activated currents. Biological membranes are essential in maintaining cell integrity and function. Neurons are surrounded by a plasma membrane and the inside of a neuron contains a large amount of potassium ions $\left(\mathrm{K}^{+}\right)$. Even though they contain a lot of positively charged potassium ions, neurons contain a large number of negatively charged proteins to balance this out (to some extent). The outside of a neuron is generally a neutral environment containing large concentrations of sodium $\left(\mathrm{Na}^{+}\right)$and chlorine $\left(\mathrm{Cl}^{-}\right)$, and smaller amounts of potassium (Koester and Siegelbaum, 2000). There are many kinds of ion channels in neuronal membranes, such as potassium channels, calcium channels and sodium channels, etc. Ion channels are targets for many toxins and chemicals. The possible effects of charged surfactants including PFOS on the modulation of ion channel function have been widely investigated. Our results obtained from cultured neurons confirm and further extend the studies by other researchers with other cell models (Ji et al., 1993; Xu and Rozanski, 1998; Harada et al., 2006). Given the amphiphilic structure, PFOS may exert its effect primarily on cell membrane. Using cell bioassay procedures, Hu et al. (2003) demonstrated that PFOS can increase the membrane fluidity and permeability through decrease in the cholesterol content of the membranes. Our findings illustrated that PFOS elevated the $\mathrm{K}^{+}$current (Figs. 2 and 3), left-ward shifted the voltage-dependent kinetics of $\mathrm{Na}^{+}$current (Fig. 4), and altered the glutamate-activated current (Fig. 5). This phenomenon is probably associated with alteration of membrane cholesterol content by PFOS and with possible actions on AMPA/kainate and NMDA receptors located on cellular membrane surface.
Ion channels play a critical role in various pathophysiological processes. For instance, $\mathrm{K}^{+}$channels may be an important determinant of cellular activities such as neural signal transduction, pacemaking and secretion to the regulation of cell volume and cell proliferation (Pongs, 1999). $\mathrm{Na}^{+}$channels produce the inward membrane current necessary for regenerative action potential production within the mammalian nervous system and are associated with the pathophysiology of pain (Waxman et al., 1999). $\mathrm{K}^{+}$ions tend to be in higher concentration inside $(135 \mathrm{mM})$ the neuron than outside $(3 \mathrm{mM})$. Also, $\mathrm{Na}^{+}$ions tend to be in higher concentration outside $(145 \mathrm{mM})$ the neuron than inside $(18 \mathrm{mM})$. When a neuron is at rest status, the plasma membrane is far more permeable to $\mathrm{K}^{+}$ions than to other ions present, such as $\mathrm{Na}^{+}$ and $\mathrm{Cl}^{-}$(Koester and Siegelbaum, 2000). Consequently $\mathrm{K}^{+}$ions diffuse out of the neuron along their concentration gradient a lot more quickly than $\mathrm{Na}^{+}$ions can move in. By using isolated cardiac ventricular myocyte as cell models, Huang et al. (1992) investigated the alterations of long-chain fatty acids in calcium channels and Ji et al. (1993) examined the modulation of voltagedependent $\mathrm{K}^{+}$and $\mathrm{Na}^{+}$currents by charged amphiphiles containing negatively charged sodium dodecylsulfate (SDS) and positively charged dodecyltrimethylammonium (DDTMA). Recently Harada et al. $(2005,2006)$ reported that PFOS markedly increased $\mathrm{Ca}^{2+}$ current and altered the steady-state activation and inactivation of $\mathrm{Ca}^{2+}, \mathrm{K}^{+}$and $\mathrm{Na}^{+}$currents toward the hyperpolarized direction. We further found that PFOS slightly elevated the amplitudes of $\mathrm{K}^{+}$ currents (both $I_{\mathrm{A}}$ and $I_{\mathrm{K}}$ ) in a dose-dependent fashion. $\mathrm{K}^{+}$channels control action potential duration and repolarization, release of neurotransmitters and hormones, and $\mathrm{Ca}^{2+}$-dependent synaptic plasticity (Müller and Bittner, 2002). $I_{\mathrm{K}}$ and $I_{\mathrm{A}}$ contribute to action potential repolarization. Since $I_{\mathrm{A}}$ is transient, repolarization is mainly related to $I_{\mathrm{K}}$. As in other neurons, $I_{\mathrm{A}}$ in hippocampal neurons was thought to modulate the timing of repetitive action potential generation and the time required to reach the threshold to fire an action potential (Gao and Ziskind-Conhaim, 1998). Enhancement of outward potassium currents leads to a reduction in cytoplasmic $\mathrm{K}^{+}$concentration, which is involved in the pathogenesis of neuronal death (Bortner et al., 1997). Thus it can be seen that PFOS might disturb the neuronal physiological processes through interference with the concentration of $\mathrm{K}^{+}$ inside/outside (cytoplasm/surface of) the neurons. Nevertheless, PFOS did not appear to affect the amplitudes of $\mathrm{Na}^{+}$currents in cultured neurons, suggesting that PFOS might specifically act on ion channels. Additionally we also found PFOS shifted the activation current-voltage curve of $\mathrm{Na}^{+}$current toward negatively potential, which is mainly due to changes in the surface potential of the cell membrane.

Three families of ionotropic glutamate receptors, discriminated pharmacologically, are present in the central nervous system (CNS). These three families are AMPA, kainate and NMDA receptors, which all belong to a broad family of ligand-gated channels (Mayer, 2005). Ionotropic glutamate receptors mediate basic information processing in the brain and excitatory responses at the majority of CNS synapses (Wollmuth and Sobolevsky, 2004), such as those that are thought to be necessary for learning and memory, developing and maintaining cellular connections, and pain perception (Bliss and Collingridge, 1993; Woolf and Salter, 2000). AMPA/kainate receptors show fast gating kinetics, desensitize strongly, are permeable to $\mathrm{Na}^{+}$and $\mathrm{K}^{+}$, and typically poorly permeable to $\mathrm{Ca}^{2+}$ (Hollmann and Heinemann, 1994). In contrast, NMDA receptors gate much more slowly, desensitize only weakly, are highly $\mathrm{Ca}^{2+}$ permeable and are blocked by extracellular $\mathrm{Mg}^{2+}$ in a strongly voltage-dependent manner (Wollmuth and Sobolevsky, 2004). Our previous work exhibited that PFOS not only increased the amplitude but also left-ward shifted the $I-V$ curves of $\mathrm{Ca}^{2+}$ currents in cultured hippocampal neurons (Liao et al., 2008). The present 
work shows that PFOS slightly elevate the $\mathrm{K}^{+}$currents and alter the steady-state activation of $\mathrm{Na}^{+}$currents toward the hyperpolarized direction. These interferences might be association with the PFOS-induced alteration of glutamate-activated currents, including both AMPA/kainate and NMDA components. As shown in Fig. 5, it is possible that the PFOS effects in the membrane have multiple actions on the ionotropic glutamate receptors. The glutamateactivated currents were increased by PFOS at low concentration and suppressed at high concentrations, showing a non-monotone dose-dependent relationship. Since these glutamate receptors are particularly relevant to possible neurotoxicity, much more experiments need to be performed to elucidate the multiple actions of PFOS on glutamate-activated currents.

Recent studies have proved various toxicities of PFOS in animals (Lau et al., 2004, 2007; Kennedy et al., 2004; Beach et al., 2006). In the previous work (Liao et al., 2008), we revealed that acute perfusion of PFOS ( $10 \mu \mathrm{M}$ and above) rapidly enhanced synaptic activity in both cultured hippocampal neurons and hippocampal brain slices, while chronic treatment with PFOS $(50 \mu \mathrm{M})$ moderately inhibited neurite outgrowth and dramatically suppressed synaptogenesis in cultured neurons. We further showed that PFOS $(10 \mu \mathrm{M}$ and above) enhanced inward $\mathrm{Ca}^{2+}$ currents and increased intracellular $\mathrm{Ca}^{2+}$ in neurons through enhancement of L-type $\mathrm{Ca}^{2+}$ channels, a mechanism that may underlie PFOS' acute effects on synaptic transmission and chronic action on neuronal development. Previous studies reported that the tissue concentrations of PFOS detected in some animals can reach $1-10 \mathrm{mg} / \mathrm{kg}$ (approximately 2-20 $\mu \mathrm{M}$ ) (Giesy and Kannan, 2001; Kannan et al., 2001). A study by Maestri et al. (2006) suggested that the concentrations of PFOS in nonoccupationally exposed human liver and brain collected from Italy were $13.6 \mathrm{ng} / \mathrm{g}(\sim 0.025 \mu \mathrm{M})$ and $1.3 \mathrm{ng} / \mathrm{g}(\sim 0.002 \mu \mathrm{M})$, respectively. Recent evidences showed that the serum level of PFOS in U.S. general population has being gradually decreased after the 2000-2002 phase-out of PFOS-related products by the primary global manufacturer, 3 M Company (Calafat et al., 2007a,b). A pilot study by Olsen et al. (2007) showed that the plasma level of PFOS in American Red Cross blood donor samples in 2005 is approximate $0.03 \mu \mathrm{M}$. Nevertheless, the serum level of PFOS is up to much higher levels, approximate $1.82 \mu \mathrm{M}$, in occupational workers (Olsen et al., 2003). Although the level of PFOS in the tissues (such as liver and brain) and blood of general population is slightly lower than the lowest dose in our experiment, the intracellular $\mathrm{Ca}^{2+}$ might still be interfered by PFOS accumulated in the body over a long time. PFOS is very stable, not readily degraded and bioaccumulative, its toxicity thereby should raise serious concerns. Recent study shows that PFOS presents moderate acute toxicity by the oral route with a rat $\mathrm{LD}_{50}$ of $251 \mathrm{mg} / \mathrm{kg}$ (UNEP, 2002). Comparably the highest dose of PFOS $(100 \mu \mathrm{M})$ used in our experiments is environmentally relevant, where the dose is comparable to the $\mathrm{LD}_{50}$ of $251 \mathrm{mg} / \mathrm{kg}$. Further, the alteration in glutamate-activated current was evident even with $1 \mu \mathrm{M}$ of PFOS application, which actually confirmed the potential damaging effects of PFOS to neurons.

In conclusion, our present results provided evidences that PFOS increased the amplitudes of two subtypes of $\mathrm{K}^{+}$currents including the transient outward current and delayed rectifier current in a similar way, negatively shifted the activation current-voltage curve of $\mathrm{Na}^{+}$current, and affect the exogenous glutamate-activated current in a dose-dependent manner. Many processes for actions of PFOS on neurons remain elusive and the underlying mechanisms still need further studies.

\section{Conflict of interest statement}

The authors declare that there are no conflicts of interest.

\section{Acknowledgements}

This work was jointly supported by grants from the National Natural Science Foundation of China, the National Basic Research Program of China, and the Chinese Academy of Sciences.

\section{References}

Andersen, M.E., Clewell III, H.J., Tan, Y.M., Butenhoff, J.L., Olsen, G.W., 2006. Pharmacokinetic modeling of saturable, renal resorption of perfluoroalkylacids in monkeys-probing the determinants of long plasma half-lives. Toxicology 227, $156-164$.

Austin, M.E., Kasturi, B.S., Barber, M., Kannan, K., MohanKumar, P.S., MohanKumar, S.M.J., 2003. Neuroendocrine effects of perfluorooctane sulfonate in rats. Environ. Health Perspect. 111, 1485-1489.

Beach, S.A., Newsted, J.L., Coady, K., Giesy, J.P., 2006. Ecotoxicological evaluation of perfluorooctanesulfonate (PFOS). Rev. Environ. Contam. Toxicol. 186, 133-174

Bliss, T.V.P., Collingridge, G.L., 1993. A synaptic model of memory: long-term potentiation in the hippocampus. Nature 361, 31-39.

Bortner, C.D., Hughes Jr., F.M., Cidlowski, J.A., 1997. A primary role for $\mathrm{K}^{+}$and $\mathrm{Na}^{+}$ efflux in the activation of apoptosis. J. Biol. Chem. 272, 32436-32442.

Burris, J.M., Lundberg, J.K., Olsen, G.W., Simpson, C.A., Mandel, J.H., 2002. Interim report no. 2, determination of serum half-lives of several fluorochemicals. St. Paul (MN), 3M Company. USEPA Docket AR-226-1086.

Butenhoff, J.L., Olsen, G.W., Pfahles-Hutchens, A., 2006. The applicability of biomonitoring data for perfluorooctanesulfonate to the environmental public health continuum. Environ. Health Perspect. 114, 1776-1782.

Calafat, A.M., Kuklenyik, Z., Reidy, J.A., Caudill, S.P., Tully, J.S., Needham, L.L., 2007a. Serum concentrations of 11 polyfluoroalkyl compounds in the U.S. population: data from the national health and nutrition examination survey (NHANES) 1999-2000. Environ. Sci. Technol. 41, 2237-2242.

Calafat, A.M., Wong, L.Y., Kuklenyik, Z., Reidy, J.A., Needham, L.L., 2007b. Polyfluoroalkyl chemicals in the U.S. population: data from the National Health and Nutrition Examination Survey (NHANES) 2003-2004 and comparisons with NHANES 1999-2000. Environ. Health Perspect. 115, 1596-1602.

Duan, S., Cooke, I.M., 1999. Selective inhibition of transient $\mathrm{K}^{+}$current by $\mathrm{La}^{3+}$ in crab peptide-secretory neurons. J. Neurophysiol. 81, 1848-1855.

Gao, B.X., Ziskind-Conhaim, L., 1998. Development of ionic currents underlying changes in action potential waveforms in rat spinal motoneurons. J. Neurophysiol. 80, 3047-3061.

Giesy, J.P., Kannan, K., 2001. Global distribution of perfluorooctane sulfonate in wildlife. Environ. Sci. Technol. 35, 1339-1342.

Giesy, J.P., Kannan, K., 2002. Perfluorochemical surfactants in the environment. Environ. Sci. Technol. 36, 146A-152A.

Harada, K., Xu, F., Ono, K., Iijima, T., Koizumi, A., 2005. Effects of PFOS and PFOA on L-type $\mathrm{Ca}^{2+}$ currents in guinea-pig ventricular myocytes. Biochem. Biophys. Res. Commun. 329, 487-494.

Harada, K.H., Ishii, T.M., Takatsuka, K., Koizumi, A., Ohmori, H., 2006. Effects of perfluorooctane sulfonate on action potentials and currents in cultured rat cerebellar Purkinje cells. Biochem. Biophys. Res. Commun. 351, 240-245.

Hollmann, M., Heinemann, S., 1994. Cloned glutamate receptors. Annu. Rev. Neurosci. 17, 31-108.

Houde, M., Martin, J.W., Letcher, R.J., Solomon, K.R., Muir, D.C.G., 2006a. Biological monitoring of polyfluoroalkyl substances: A review. Environ. Sci. Technol. 40, 3463-3473.

Houde, M., Bujas, T.A.D., Small, J., Wells, R.S., Fair, P.A., Bossart, G.D., Solomon, K.R., Muir, D.C.G., 2006b. Biomagnification of perfluoroalkyl compounds in the bottlenose dolphin (Tursiops truncatus) food web. Environ. Sci. Technol. 40, 4138-4144.

Hu, W., Jones, P.D., Upham, B.L., Trosko, J.E., Lau, C., Giesy, J.P., 2002. Inhibition of gap junctional intercellular communication by perfluorinated compounds in rat liver and dolphin kidney epithelial cell lines in vitro and Sprague-Dawley rats in vivo. Toxicol. Sci. 68, 429-436.

Hu, W., Jones, P.D., De Coen, W., King, L., Fraker, P., Newsted, J., Giesy, J.P., 2003. Alterations in cell membrane properties caused by perfluorinated compounds. Comp. Biochem. Physiol. C: Toxicol. Pharmacol. 135, 77-88.

Huang, J.M., Xian, H., Bacaner, M., 1992. Long-chain fatty acids activate calcium channels in ventricular myocytes. Proc. Natl. Acad. Sci. U.S.A. 89, 6452-6456.

Ji, S., Weiss, J.N., Langer, G.A., 1993. Modulation of voltage-dependent sodium and potassium currents by charged amphiphiles in cardiac ventricular myocytes. Effects via modification of surface potential. J. Gen. Physiol. 101, 355-375.

Kannan, K., Franson, J.C., Bowerman, W.W., Hansen, K.J., Jones, P.D., Giesy, J.P., 2001 Perfluorooctane sulfonate in fish-eating water birds including bald eagles and albatrosses. Environ. Sci. Technol. 35, 3065-3070.

Kannan, K., Corsolini, S., Falandysz, J., Oehme, G., Focardi, S., Giesy, J.P., 2002. Perfluorooctanesulfonate and related fluorinated hydrocarbons in marine mammals, fishes, and birds from coasts of the Baltic and the Mediterranean Seas. Environ. Sci. Technol. 36, 3120-3126.

Kennedy, G.L., Butenhoff, J.L., Olsen, G.W., O’Connor, J.C., Seacat, A.M., Perkins, R.G., Biegel, L.B., Murphy, S.R., Farrar, D.G., 2004. The toxicology of perfluorooctanoate. Crit. Rev. Toxicol. 34, 351-384.

Koester, J., Siegelbaum, S.A., 2000. Membrane potential. In: Kandel, E.R., Schwartz, J.H., Jessell, T.M. (Eds.), Principles of Neural Science. McGraw-Hill, New York, pp. 125-139. 
Lau, C., Butenhoff, J.L., Rogers, J.M., 2004. The developmental toxicity of perfluoroalkyl acids and their derivatives. Toxicol. Appl. Pharmacol. 198, 231-241.

Lau, C., Anitole, K., Hodes, C., Lai, D., Pfahles-Hutchens, A., Seed, J., 2007. Perfluoroalkyl acids: a review of monitoring and toxicological findings. Toxicol. Sci. 99, 366-394.

Liao, C.Y., Li, X.Y., Wu, B., Duan, S.M., Jiang, G.B., 2008. Acute enhancement of synaptic transmission and chronic inhibition of synaptogenesis induced by perfluorooctane sulfonate through mediation of voltage-dependent calcium channel. Environ. Sci. Technol. 42, 5335-5341.

Maestri, L., Negri, S., Ferrari, M., Ghittori, S., Fabris, F., Danesino, P., Imbriani, M., 2006. Determination of perfluorooctanoic acid and perfluorooctanesulfonate in human tissues by liquid chromatography/single quadrupole mass spectrometry. Rapid Commun. Mass Spectrom. 20, 2728-2734.

Martin, J.W., Muir, D.C.G., Kwan, W.C., Moody, C.A., Ellis, D.A., Solomon, K.R., Mabury, S.A., 2002. Collection of airborne fluorinated organics and analysis by gas chromatography chemical ionization-mass spectrometry. Anal. Chem. 74, 584-590.

Mayer, M.L., 2005. Glutamate receptor ion channels. Curr. Opin. Neurobiol. 15 (3), 282-288.

Meyers, D.E.R., Graf, R.A., Cooke, I.M., 1992. Ionic currents of morphologically distinct peptidergic neurons in defined culture. J. Neurophysiol. 67, 1301-1315.

Müller, W., Bittner, K., 2002. Differential oxidative modulation of voltage-dependent $\mathrm{K}^{+}$currents in rat hippocampal neurons. J. Neurophysiol. 87, 2990-2995.

Olsen, G.W., Burris, J.M., Burlew, M.M., Mandel, J.H., 2003. Epidemiologic assessment of worker serum perfluorooctanesulfonate (PFOS) and perfluorooctanoate (PFOA) concentrations and medical surveillance examinations. J. Occup. Environ. Med. 45, 260-270.

Olsen, G.W., Mair, D.C., Reagen, W.K., Ellefson, M.E., Ehresman, D.J., Butenhoff, J.L., Zobel, L.R., 2007. Preliminary evidence of a decline in perfluorooctanesulfonate (PFOS) and perfluorooctanoate (PFOA) concentrations in American Red Cross blood donors. Chemosphere 68, 105-111.
Pongs, O., 1999. Voltage-gated potassium channels: from hyperexcitability to excitement. FEBS Lett. 452, 31-35.

Renner, R., 2001. Growing concern over perfluorinated chemicals. Environ. Sci. Technol. 35, 154A-160A.

Richmond, J.E., Sher, E., Cooke, I.M., 1995. Characterization of the $\mathrm{Ca}^{2+}$ current in freshly dissociated crustacean peptidergic neuronal somata. J. Neurophysiol. 73 2357-2368.

Shen, W., Wu, B., Zhang, Z., Dou, Y., Rao, Z.R., Chen, Y.R., Duan, S., 2006. Activityinduced rapid synaptic maturation mediated by presynaptic cdc42 signaling. Neuron 50, 401-414.

Taniyasu, S., Kannan, K., So, M.K., Gulkowska, A., Sinclair, E., Okazawa, T., Yamashita, N., 2005. Analysis of fluorotelomer alcohols, fluorotelomer acids, and short- and long-chain perfluorinated acids in water and biota. J. Chromatogr. A 1093, 8997.

United Nations Environment Programme (UNEP), 2002. Regional Reports of the Regionally Based Assessment of Persistent Toxic Substances Program 2002. Available at http://www.chem.unep.ch/pts.

Waxman, S.G., Dib-Hajj, S., Cummins, T.R., Black, J.A., 1999. Sodium channels and pain. Proc. Natl. Acad. Sci. U.S.A. 96, 7635-7639.

Wollmuth, L.P., Sobolevsky, A.I., 2004. Structure and gating of the glutamate recepto ion channel. Trends Neurosci. 27 (6), 321-328.

Woolf, C.J., Salter, M.W., 2000. Neuronal plasticity: increasing the gain in pain. Science $288,1765-1769$.

Xu, Z., Rozanski, G.J., 1998. $\mathrm{K}^{+}$current inhibition by amphiphilic fatty acid metabolites in rat ventricular myocytes. Am. J. Physiol. 275, C1660-C1667.

Yeung, L.W., So, M.K., Jiang, G., Taniyasu, S., Yamashita, N., Song, M., Wu, Y., Li, J., Giesy, J.P., Guruge, K.S., Lam, P.K., 2006. Perfluorooctanesulfonate and related fluorochemicals in human blood samples from China. Environ. Sci. Technol. 40, 715-720. 